\title{
Vane shear rheometer test to demonstrate the debris flow initiation characteristics and phenomena
}

\author{
Zhonggang Liu ${ }^{1}$. Enzhi Wang ${ }^{1}$. Xiaoli Liu¹. Sijing Wang ${ }^{1}$
}

\begin{abstract}
KEYWORDS: Initiation process, Vane shear rheometer, Strain, Strain rate, Strain acceleration.
\end{abstract} ABSTRACT The primary question in the debris flow initiation study is differentiation of the initiation process from other processes. This paper introduced a new experimental method and apparatus which can apply artificial rain, detect deformation, resistance and other variables. Based on the experimental data analysis, the definition of debris flow initiation process was promoted and demonstrated. Debris flow initiation is defined as the period in which the strain acceleration of soil mass is greater than zero. The experiment mainly focused on four aspects during the debris flow initiation process: (i) the paper analyzed a series of variables detected by the experiment (strain, resistance, water content and pore-water pressure), (ii)initiation process was defined by the key variable of strain and its propagations, (iii) in order to facilitate further study, initiation process was distinguished into initiation and acceleration processes, (vi) the characteristics of debris flow initiation process was studied. Finally, the experiment results can be used to describe many phenomena such as the abrupt nature of debris flow disasters.

\section{INTRODUCTION}

Debris flow initiation is influenced by geological conductions, earthquakes (Cui, 2011;Xu, 2012), geomorphology, weathering (Floris, 2010) and external geomorphic agency(Susan, 2000; Parise, 2012), therefore most soil materials can be initiated in an unconsolidated state. Those materials are easily triggered by inducing factors including rainfall (Chen, 2006; Tang, 2011; Chen, 2013; Vennari, 2014), snow-melt (Butler and Walsh,1994; Sumio Matsuura, 2013 ) glacial melt

(Pierson,1990) or dam failure( Raphael Worni, 2012; Matra, 2007), which act on the debris flow initiation in different ways. Surveys and studies indicate that rainfall-induced debris flow is the most common pattern, and several relationships have been established between the initiation and the intensity and duration of rainfall (Wieczorek, 1987; Lorenzo Marchi, 2002).

Recently, researchers have confirmed the phenomenon and process of rainfall-induced debris flow by experimental and field studies, and the initiation phenomenon has been described in details and important principles and models have been achieved. Those studies mainly focus on the following aspects: description of the initiation process of rainfall-induced debris flow, the pore water pressure evolution during this process (Chen, 2010;Wang, 2003;Iverson, 1997a,1997b; Chen and Cui 2006), influences of the soil grain friction (Chen,2004,2010) and the failure process of the soil mass (Anderson,1995). Those aspects affect the debris flow initiation by changing the property and strength of the soil material, which destroy the balance of the soil mass and result triggering the debris flow. Meanwhile, a series of research focuses on the debris flow rheology (Iverson RM, 2003; Sueng, 2010), which is also affected by many factors such as grain size. Those studies have proved the initiation process with rainfall, described the phenomena of initiation process and developed a series of debris flow rheology. In most of these studies, the initiation process have been determined by visual evidence, while it should have been determined by quantified variables which can give the precise time of initiation and period of initiation process.

In order determine the initiation process, a new experiment was carried out in which the resistance and strain (strain rate) can be measured from soil mass in stability to debris flow. Through this experiment, this paper attempts to develop the definition of debris flow initiation and the initiation process with a key variable (strain). Further analysis was carried out when the initiation process was determined precisely, such as the characteristics of debris flow initiation. 


\section{EXPERIMENT METHOD}

\section{Material}

Soil materials are composed of particles that vary in size: fine sand, silt and clay. Soil grain size distributions are obtained from the grain analysis test (as shown in Fig1 A). The main geotechnical parameters are summarized in Table 1. The mineral composition (given in Fig.1 B) shows that only $1.31 \%$ compositions are inflation minerals

Table 1 The main geotechnical parameters of soil mass

\begin{tabular}{ccccc}
\hline $\boldsymbol{w}_{\boldsymbol{L}}(\%)$ & $\boldsymbol{w}_{\boldsymbol{P}}(\%)$ & $\boldsymbol{w}(\%)$ & $\boldsymbol{I}_{\boldsymbol{P}}(\%)$ & $\boldsymbol{G}$ \\
\hline 25.0 & 11.7 & 13.4 & 13.3 & 2.64 \\
\hline
\end{tabular}

$\boldsymbol{w}_{\boldsymbol{L}}=$ liquid limit; $\boldsymbol{w}_{\boldsymbol{p}}=$ plastic limit, $\boldsymbol{w}=$ moisture content; $\boldsymbol{G}=$ specific density.

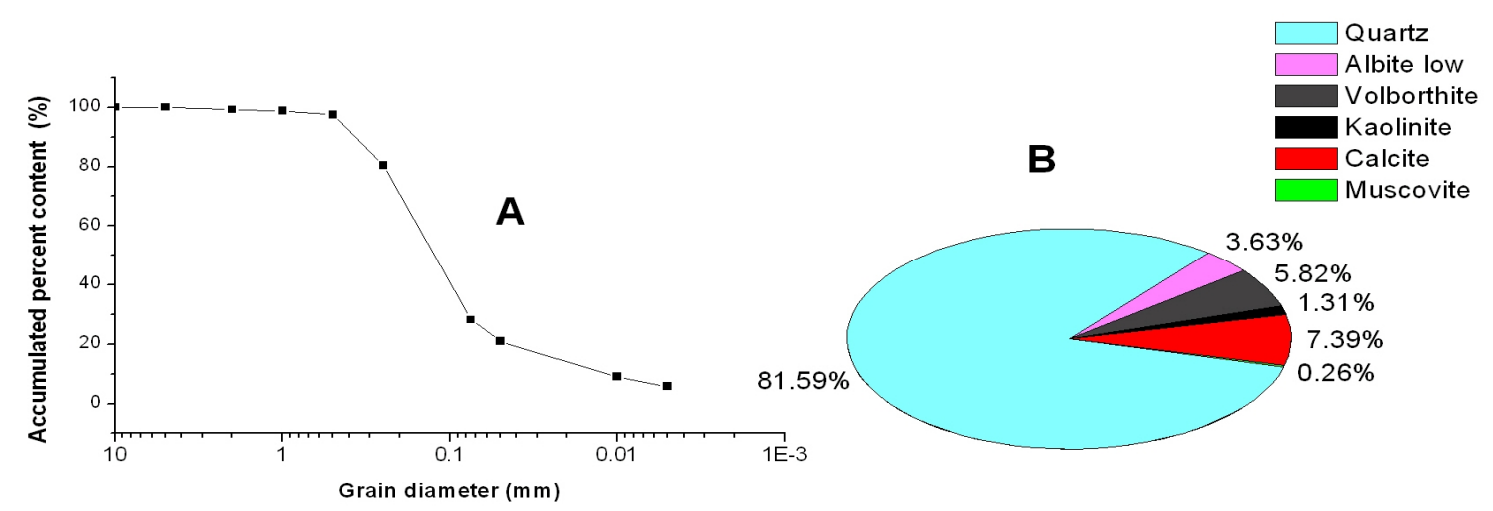

Fig.1 Particle size distribution and mineral composition of experimental material.

\section{Apparatus}

In order to measure the strain (deformation) or strain rate, an improved vane-shear apparatus is applied as the main apparatus in this study, and it is named the vane shear rheometer (shown in Fig.2). This apparatus is composed by optical-electricity encoder (A), DC torque motor (B), torque transducer (C), four-bladed vane (D) and rod. The torque (shear stress) can be outputted and measured using this apparatus, the rotation angle (strain or strain rate) of the soil mass can be measured by it as well. Other transducers are used in this study, which includes a pore-water pressure sensor and moisture content sensors.

Accessory equipment includes the artificial rain system which is used to change the moisture of the soil mass, and it comprises a water pump, water tank, sprinkler and water pipe. 


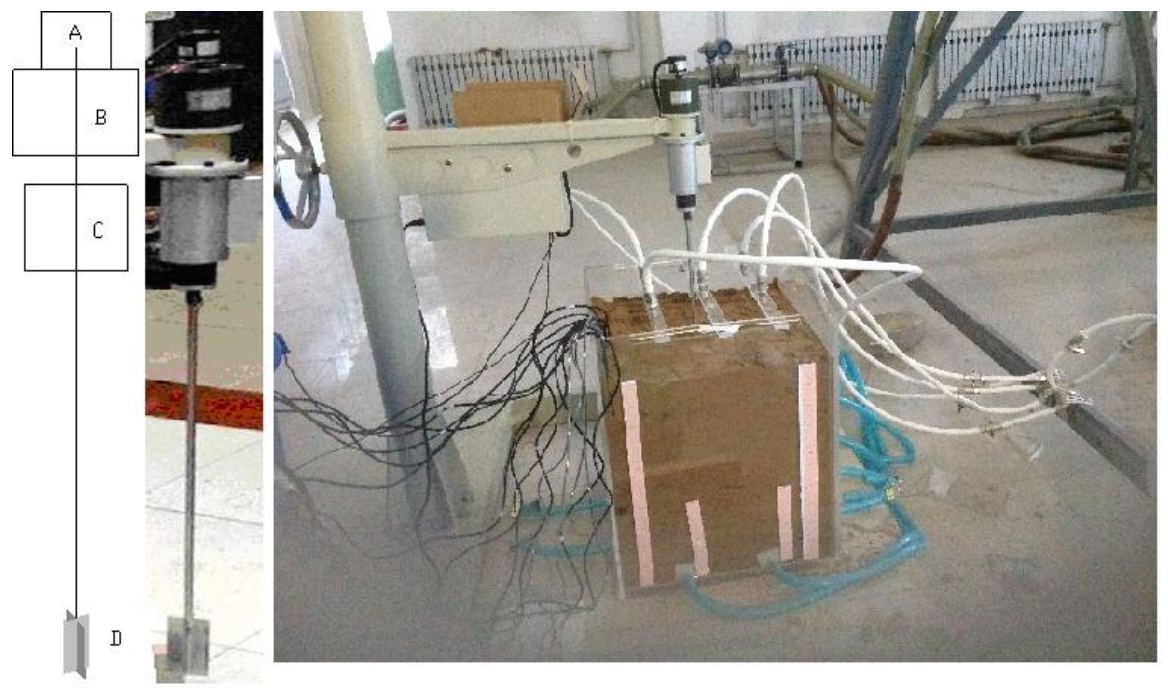

Fig.2 Vane shear rheometer.

\section{Torque - shear stress}

The torque is outputted by the DC torque motor (B) which provides torque hovering at $0-2 \mathrm{Nm}$, transmits to the vane $(5 \mathrm{~cm}$ in diameter and $10 \mathrm{~cm}$ in height) by the rod and finally applies this to the material finally. The value of torque is measured by the torque transducer $(C)$ which is installed under the torque motor.

\section{Rotation angle - strain}

Once the torque is applied to the soil mass, the rotation angle will generate on a soil column formed by the vane as deformation develops in the soil mass. The rotation angle is measured by the optical-electricity encoder (A) which is installed above the torque motor and sends out 10000 pulses when the vane rotates $360^{\circ}$. This angle can be used to calculate the shear strain and strain rate.

\section{Other parameters}

Soil moisture is measured by a series of moisture content sensor (with the maximum volumetric water content of $50 \%$, with a $2 \%$ error rate), and the pore-water pressure is measured by a pore-water pressure sensor (the range is $2.2 \mathrm{~m}$ for the water column and the precision is $2 \mathrm{~mm}$ for the water column; the operating temperature range is between 0 and 40 degrees centigrade).

\subsection{Experiment parameter diagram}

In the experiments, soil mass is accumulated in the flume $(0.5 \mathrm{~m} \times 0.5 \mathrm{~m} \times 0.5 \mathrm{~m})$ and its appearance density is $16.12 \mathrm{kN} / \mathrm{m}^{3}$. The top and bottom of the vane is buried $20 \mathrm{~cm}$ and $30 \mathrm{~cm}$ below the sample surface respectively. The pore-water pressure sensor is embedded $25 \mathrm{~cm}$ below the sample surface, 5 moisture content sensors are embedded $5 \mathrm{~cm}, 15 \mathrm{~cm}, 25 \mathrm{~cm}, 35 \mathrm{~cm}$ and $45 \mathrm{~cm}$ below the sample surface. The torque is $0.6 \mathrm{~N}$.m outputted by the motor which can be transformed into the slope angle at about $30^{\circ}$. A artificial rain system is applied to make the soil increase in moisture content intermittently.

\section{EXPERIMENT RESULT AND DEBRIS FLOW INITIATION PROCESS}

\section{Definition of debris flow initiation process}

Initiation means the initial velocity changes (usually increases) on the object. As to the debris flow initiation process, it can be defined as the process in which the initial velocity (usually equals to null ) of soil mass increases to migration velocity. As from the definition, the strain (or displacement) grows nonlinearly and the velocity increases, which mean the acceleration is greater than zero. Hence, the initiation process can be distinguished by the study on strain and its derived variables in the experiments. In turn, the initiation can be studied more accurately.

\section{Shear strain}

Shear strain (Fig.4, A) is calculated by the pulse (N) sent out by the optical-electricity encoder $\left(\gamma=\frac{N}{10000} \times \frac{1}{360}\right)$. Strain is seen as the most important data which is used to define the initiation 
process and achieve the strain rate $\left(\dot{\gamma}=\frac{d \gamma}{d t}\right)$ and acceleration $\left(a=\frac{d \dot{\gamma}}{d t}\right)$. Strain combines with the strain rate and acceleration which can determine the initiation process.

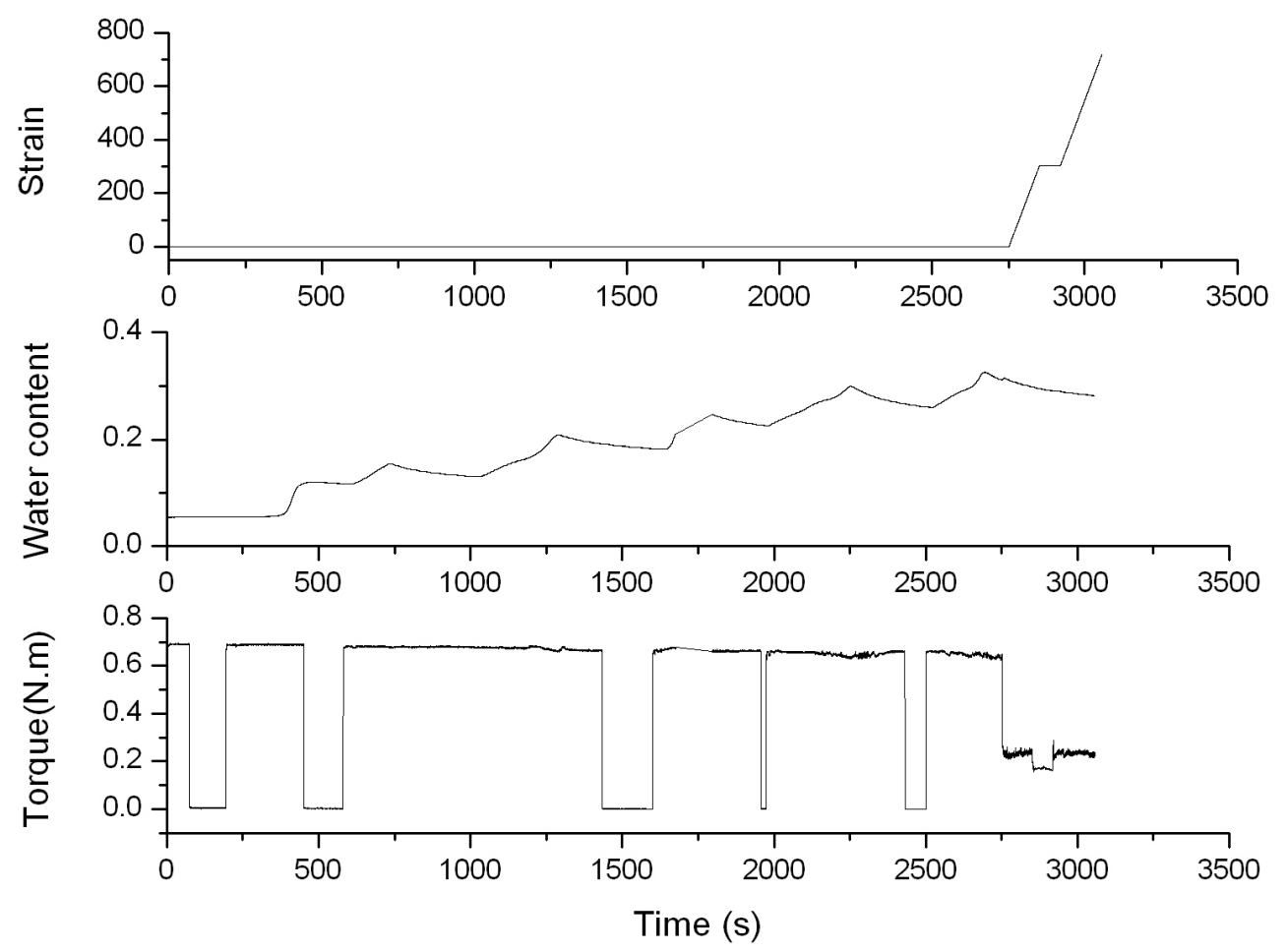

Fig.3 Time sequence of the experiment data

It is easy to see from Fig.3 (A) that the strain has grown linearly since the time around 2750s. Here, data hovering from 2750 s to 2760 s (Fig.3) will be studied in detail to search the initiation process and initiation point and investigate the characteristics of the process.

\section{Initiation process}

Fig. 5 shows that the strain increases non-linearly from around 2752s. Then, in order to facilitate the initiation process analysis, the strain rate and acceleration was given in Fig.4 during the time from 2750 s to $2754 \mathrm{~s}$.

\section{Determination of the initiation process}

The strain acceleration appears positive until 2750.9s and lasts to 2752.2s, and the increase of the strain rate can be distinguished into three stages: (i) increasing slightly from zero in the time between $2750.9 \mathrm{~s}$ to $2751.6 \mathrm{~s}$, (ii) increasing rapidly in the time between $2751.6 \mathrm{~s}$ to $2752.2 \mathrm{~s}$;(iii) fluctuating and achieving the constant value after 2752.2s. Here, the initiation process and point can be determined according to the definition of the initiation and its process: the initiation process has lasted from $2750.9 \mathrm{~s}$ to $2752.2 \mathrm{~s}$, and the initiation has occurred at $2750.9 \mathrm{~s}$ in the experiment.

\section{Characteristics of the debris flow initiation process}

The experimental results achieve a series of data which reveal characters of the debris flow initiation process.

It is clearly shown that the initiation process can be characterized by the strain rate growing with an unequal acceleration. The peak value of the acceleration appears at the middle of the process.

Soil mass decreases in resistance during the initiation process as revealed by the analysis of the torque measured in the experiment. The experimental result shows that the change of torque experience three stages: (i) decreasing slightly near the initiation point, (ii) decreasing drastically in sub-second in the middle of the process, and (iii) decreasing gently to the residual resistance in the end of this period. 
The pore water pressure grows in the initiation process while the volume water content does not increase any more, which indicates that soil mass reaches its maximum water-holding capacity in the process and the pore water pressure accumulates with the soil deformation.

It can be seen from Fig. 3 that a long-term deformation process is available before the debris flow initiation, which means there is a creep property in the soil mass.

Those characteristics agree with the phenomena of debris flow initiation in several aspects:
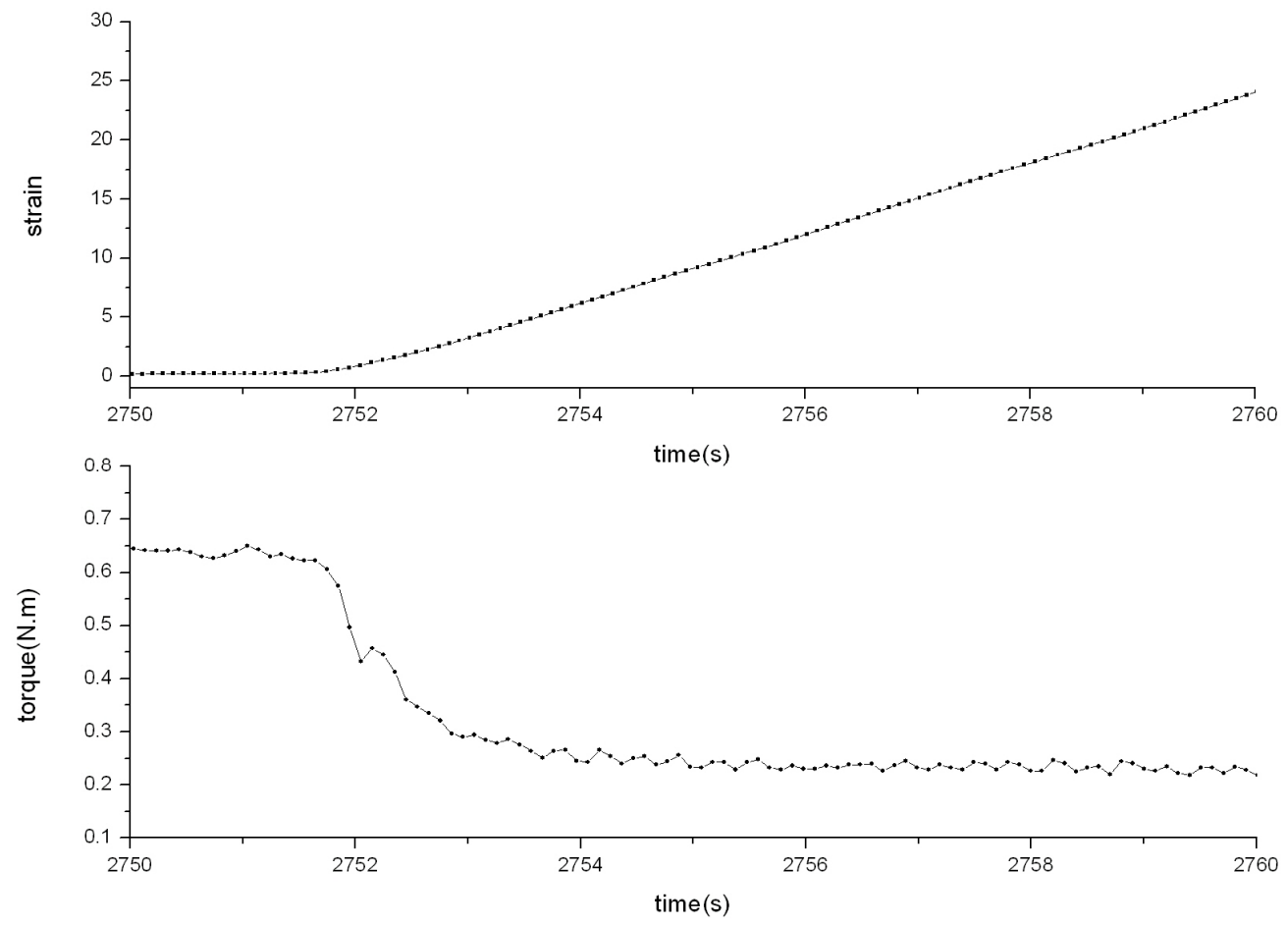

Fig.4 Time sequence of strain and torque of the initiation process

Resistance degradation process provides a hint to demonstrate the initiation phenomena desired by Chen's experiment (Chen, 2010): at the beginning of the initiation process fractures generate, then, extend in the soil mass; eventually, it goes to failure and debris flow initiates. Those phenomena result in the resistance slightly, drastically and gently decreasing during the initiation process.

Initiation process is accompanied by the pore water pressure rising which makes the soil mass decrease in effective stress and liquefaction, which has been demonstrated by Iverson's experiment (Iverson, 1997a, 1997b).

The abrupt nature can be explained by the experiment result that the initiation process completes in a few seconds. Compared to the experiment duration which lasts more than 2750s, the initiation process can be treated as transient 


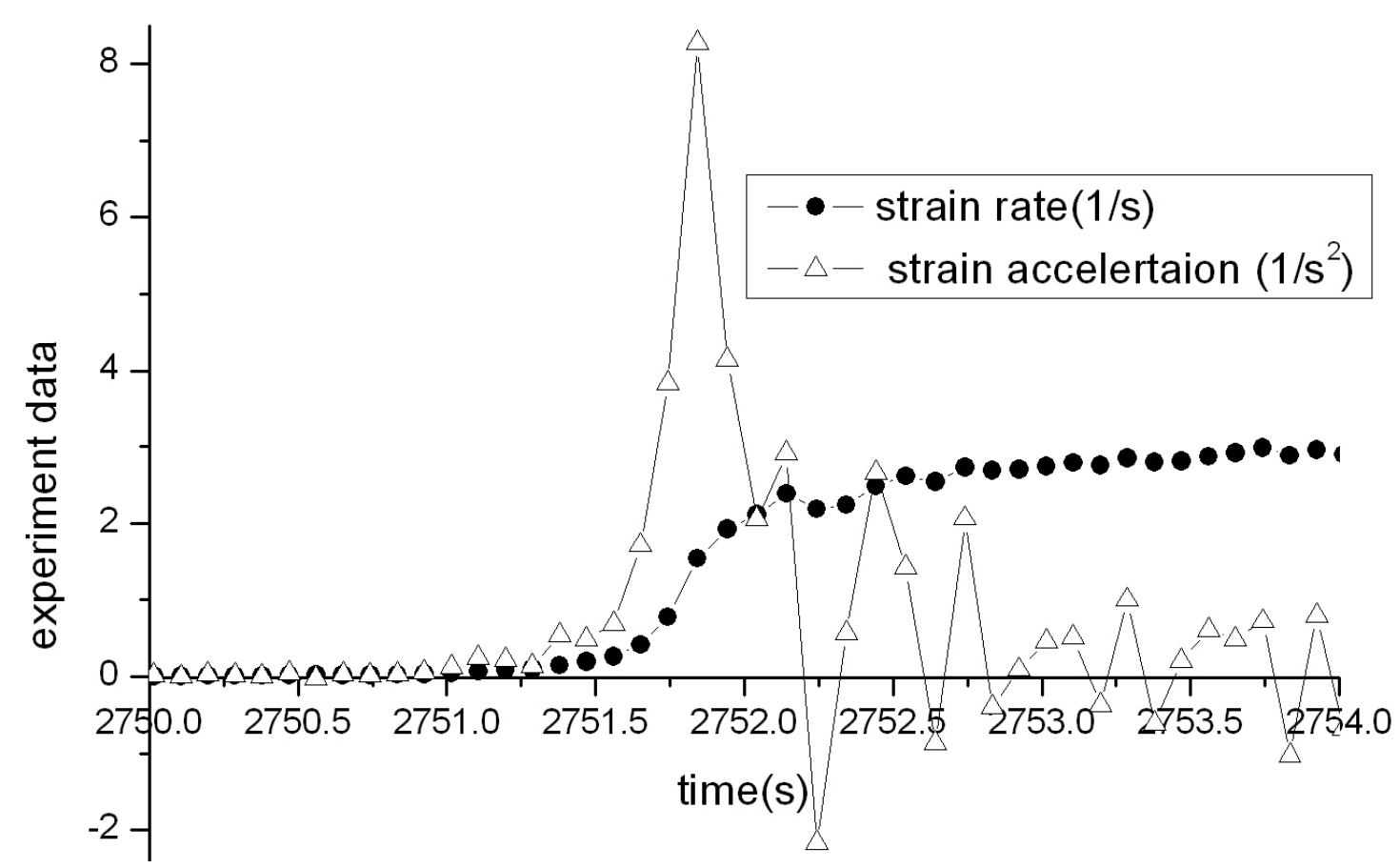

Fig.5 Strain rate acceleration of the initiation process

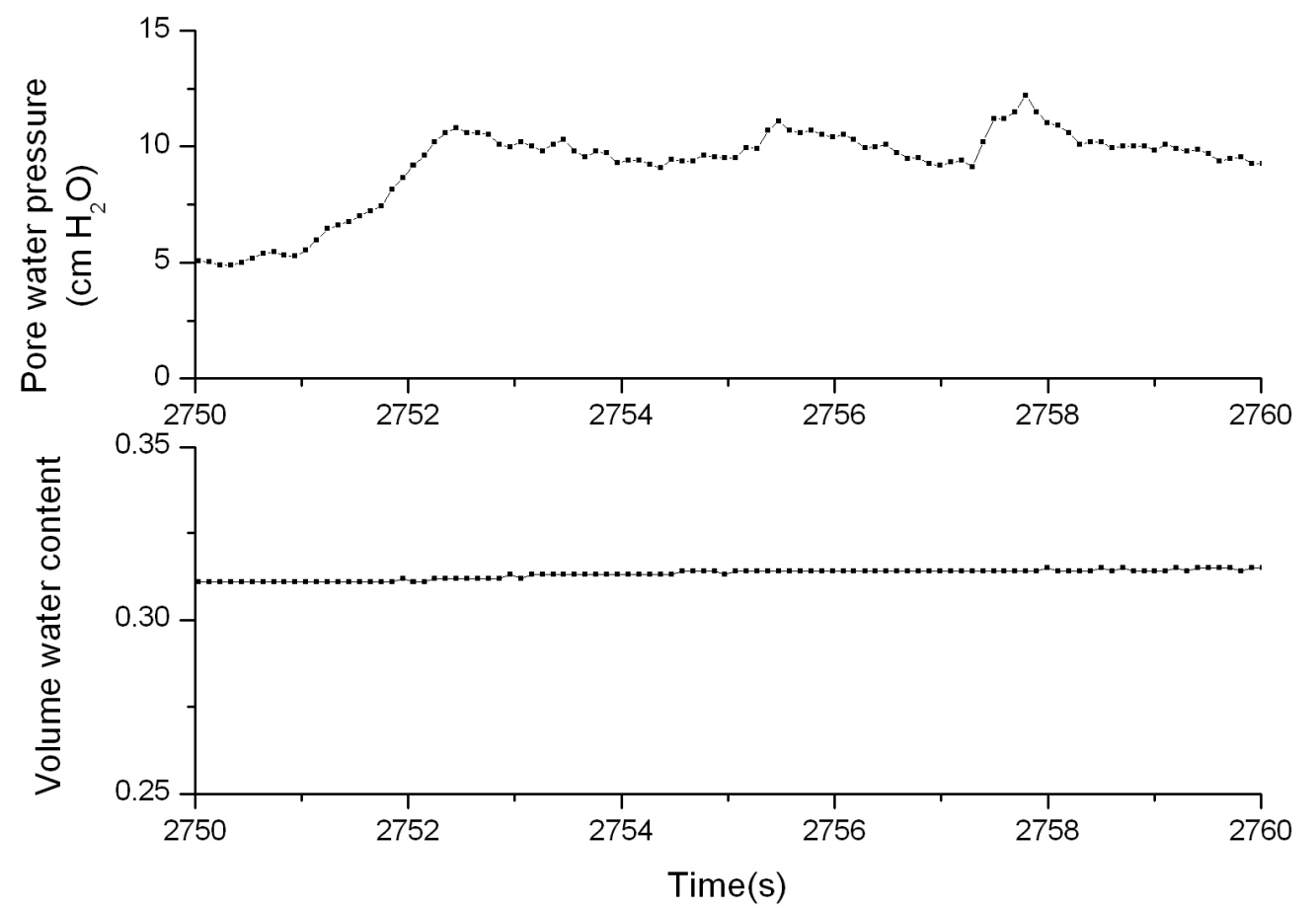

Fig.6 Pore water pressure and water content evolution during the initiation process

\section{CONCLUSIONS AND DISCUSSIONS}

\section{Conclusions}

As the primary question in the debris flow initiation study is the determination of the initiation process which was usually estimated by the visual phenomena on the surface of the soil mass, this paper shows a tentative definition by the strain (strain rate and acceleration), which has explicit physical meaning and is measurable and quantifiable. Three stages can be distinguished by this definition in a whole process of debris flow: before initiation, initiation process, and liquefaction and fluid. A new experiment was carried out to exam this definition and several conclusions ware achieved when the experiment result was compared with the definition. 
It is reasonable to define the debris flow initiation process with strain, because there is obvious change in the time-strain relationship around the period of initiation process. Meanwhile, the strain acceleration is positive in this period.

A series of useful hints have been acquired to demonstrate the phenomena of the debris flow when analysis focuses on the initiation process: (i) the initiation process is of such short duration that it can be treated as transient compared with the experiment duration, the sudden character of debris flow can be explained by this conclusion,(ii) soil mass resistance has decreased during the initiation process, which means that it can be fluid with the low driving force after initiation. This is the reason why the debris flow can migrate over long distances along the gentle gully while it is usually triggered on the steep slop, (iii) the experimental result shows that debris flow initiation is the result of the combination of increases in strain and pore-water pressure and decreases in resistance with the maximum volume water content.

\section{Discussions}

In favor of detecting the strain (deformation) the experiment has been conducted by the four-blade vane shear Rheometer. There are aspects that can not be fully accounted for in the real debris flow initiation, such as the infiltration.

There is creep property on the soil mass as the volume water increases before the initiation, and there is gap in resistance before and after initiation. A model should have been established to describe this phenomenon, which will be studied in the future.

\section{ACKNOWLEDGMENTS}

This work was supported by the Chinese National Science Foundation (U1361103).

\section{REFERENCES}

[1] Butler, D.R., Walsh, S. J., 1994. Site characteristics of debris flows and their relationship to alpine treeline.Physical Geography15:181-199.

[2] Chen.N., Cui.P., et al. 2004. Testing study on strength reduction of gravelly soil in triggering area of debris flow under earth. Chinese journal of rock mechanics and engineering 23(16):2743-2747(in Chinese)

[3] Chen.X.Q., Cui.P., et al. 2006. Artificial rainfall experimental study on landslide translation to debris flow.. Chinese journal of rock mechanics and engineering 25(1):106-116(in Chinese)

[4] C.Tang, N.Rengers, et al. 2011, Triggering conditions and depositional characteristics of a disastrous debris flow event in Zhouqu city,Gansu, Province, north western China. Nat. Hazards. Earth Syst. Sci., 11: 2903-3912.

[5] C.vennari, S.L. Gariano, et al. 2014. Rainfall thresholds for shallow landslide occurrence in Calabria southern Italy, Nat. Hazards Earth Syst. Sci.,14,317-330.

[6] Gerald. F. Wieczorek. 1987. Effect of rainfall intensity and duration on debris flows in central Santa Cruz Mountains, California. Geological Society of America, Reviews in Engineering Geology, Volume VII:93-104

[7] Gonghui Wang. Kyoji Sassa. 2003. Pore-pressure generation and movement of rainfall-induced landslides: effects of grain size and fine-particle content. Engineering Geology 69:109-125.

[8] Hongey Chen, Simon Dadson, Yi-Guan Chi. 2006. Recent rainfall-induced landslides and debris flow in northern Taiwan. Geomorphology. 77:112-125.

[9] Iverson,.R.M.,1997a. The physics of debris flows. Reviews of Geophysics 35(3):245-296.

[10]Iverson.R.M, Reid. M., Lahusen.R.G, 1997b. Debris-flow mobilization from landslides.Annual Review of Earth and Planetary Sciences 25:85-138.

[11]Iverson RM .2003. The debris-flow rheology myth. In: Rickenmann D, Chen C-I (eds) Proceedings of third international conference on debris-flow hazard mitigation: mechanics, prediction, and assessment. Millpress, Rotterdam, pp 303-314.

[12]J. C. Chen, C. D. Jan, and W. S. Huang. 2013. Characteristics of rainfall triggering of debris flows in the Chenyuanlan watershed, Taiwan. Nat. Hazards Earth Syst. Sci.,13,1015-1023. 
[13]Lorenzo Marchi. Massimo Arattano. Andrea M. Deganutti. 2002. Ten years of debris-flow monitoring in the Moscardo Torrent （Italian Alps）. Geomorphology 46:1-17.

[14]Marta Chiarle. Sara Iannotti, et al. 2007. Recent debris flow occurrences associated with glaciers in the Alps. Global and Planetary Change 56:123-136.

[15]M. Floris, A. D'Alpaos, et al. 2010. Recent changes in rainfall characteristics and their influence on thresholds for debris flow triggering in the Dolomitic area of Cortina d'Ampezzo, North-eastern Italian Alps. Nat. Hazards. Earth Syst.Sci.,10:571-580

[16]M. Parise, S. H. Cannon, 2012, Wildfire impacts on the processes that generate debris flows in burned watersheds. Nat. Hazards,61, 217-227.

[17]N. Sh. Chen. W. Zhou. et al. 2010. The processes and mechanism of failure and debris flow initiation for gravel soil with different clay content. Geomorphology 121:222-230.

[18]N.Sh. Chen. Z.Q.Yue. et al. 2007. A rational method for estimating maximum discharge of a landslide-induced debris flow: A case study from southwestern China. Geomorphology 84:44-58.

[19]Peng Cui, Xiao-Qing Chen, et al. 2011, The Wenchuan earthquake (May 12, 2008), Schuan Province, China, and resulting geohazards. Nat. Hazards,56:19-36.

[20]Pierson TC, Janda RJ, et al. 1990. Perturbation and melting of snow and ice by the 13 November 1985 eruption of Nevado del Ruiz, Columbia and consequent mobilization, flow and deposition of lahars. J, volcanol. Geotherm. RES.41:17-66.

[21]Q. Xu, S. Zhang, et al. 2012. The 13 august 2010 catastrophic debris flows after the 2008 Wenchuan earthqueak, China. Nat. Hazards. Earth Syst. Sci., 12:201-216

[22]Raphael Worni, Markus Stoffel, et al. 2012. Analysis and dynamic modeling of a moraine failure and glacier lake outburst flood at ventisquero Negro, Patagonian Andes (Argentina). Journal of Hydrology 444-445:134-145.

[23] Sueng Won Jeong, 2010,Grain size dependent rheology on the mobility of debris flows. Geosciences Journal.14(4):359-369.

[24] Sumio Matsuura, Takashi Okamoto et al. 2013. Characteristics of meltwater and/or rainfall regime in a snowy region and its effect on sediment-related disasters. Bull Eng Geol Environ, 72:119-129

[25] Susan H. Cannon, Steven L. Reneau. 2000, Conditions for generation of fire-related debris flows, Capulin Canyon, New Mexico, Earth surf. Process. Landforms 25:1103-1121. 